\title{
Is (earth) science only made for everyone who speaks English?
}

DASAPTA ERWIN IRAWAN AND ARIF SUSANTO

Institut Teknologi Bandung

Presenting Author: r-win@office.itb.ac.id

Science comes from anyone and be made for all. But with the current research situation, we need to redefine it. Our experiments use volcanology themes (Mount Krakatau, Mount Merapi) and disaster themes (Aceh Tsunami and Flood) which can be found in scientific databases (commercial and non-profit) to determine the extent of the collaboration of geoscience researchers in the world and how they build knowledge from prior knowledge.

Some of the earliest indications we found: (1) international collaboration has occurred with the majority of research funding flowing from the northern hemisphere. This will (automatically) determine: who is the first author, what language is used (not Indonesian), the journal that published it (not Indonesian journal), (2) the first and second points have the potential to distance science from the main stakeholders (local communities), (3) minimal references to articles written in Indonesian.

Based on these indications, it is time for us to change the way of scientific communication, especially if the object of our research is in a country that does not use English as the main language. Scientific publications need to be returned to their main function as tools for dissemination, rather for selfpromotion. We need to go a step further than the science communication we are doing today.

Open access means both accessible documents and accessible language. 